\title{
INTERVIEW WITH ALEX STONER
}

\author{
INTERVIEW CONDUCTED \\ BY:
}

DANNY ALVORD

University of Kansas

Dr. Alex Stoner is assistant professor of Sociology at Salisbury University. His work focuses on critical theory and political economy of the environment. His work has appeared in journals such as Logos, and Critical Sociology. Dr. Stoner is also the recipient of the 2013 Albert Szymanski and T.R. Young Graduate Student Paper Award, given out by the American Sociological Association's Marxist Sociology Section. Dr. Stoner joined us to discuss his current work on the critique of the concept of the Anthropocene, as well as the need to develop a critical theory of the environment.

ALVORD: Dr. Stoner, welcome. Thank you so much for joining us. It's a real pleasure to have you here.

STONER: Thank you.

ALVORD: So, just to start off, I was wondering if you could tell us a bit about how you think about your research, or what your research agenda, broadly speaking, is.

STONER: My main areas of expertise, research areas, are social theory, specifically I am more interested in critical theory, especially the early Frankfurt School and Adorno in particular. Then I'm also focusing on the political economy of the environment within environmental sociology - taking a politicaleconomic approach to global environmental problems. There's also really interesting work that's been done with regards to the political economy of the environment, especially in the past few decades.

Social Thought and Research, Vol. 34 
ALVORD: What was your path into these areas?

STONER: Well, I should mention that in terms of my research agenda, which I didn't get to, there's lots of really good work on political economy of the environment. Looking at the big structural drivers of environmental problems: World Systems perspective, or other types of approaches that are getting at this type of stuff. It's quite disturbing, in terms of the objective drivers of global environmental problems, so you can see-you can paint a picture of this - after 1750, humans' destruction of the environment increases and it spikes again during the latter half of the twentieth century. Like I said, lots of people have done some interesting work looking in to the political and economic factors that are driving these changes. What I'm interested in is how that's related to the subject of the environment-society problem. In other words, how people conceive and understand the natural environment. And that's really what I've been trying to figure out and bring a specific focus on what my research is. From my perspective, there is a connection between these objective drivers and the subject of the human machine. How we understand the problems, how we see the natural environment, how we understand "Nature." So I'm really trying to connect the two.

ALVORD: So towards that end, your article that appears in Critical Sociology on sociobiophysicality, you raise this super interesting paradox that as degradation of the environment has increased, so too has our awareness of the problem-with seemingly more and more... we don't know what to do about it, even though we are more aware of the problem. I wonder if you could just speak to that interesting paradox that you have identified.

STONER: Right. To back up just a little bit, like I said, with this general picture we can see basically with the Industrial Revolution during the latter half of the eighteenth century, if we just look at $\mathrm{CO}_{2}$ concentrations, which is a good proxy for anthropogenic causes of environmental degradation. We see this spike, and then it increases, but it takes off after 1950 - and this is the period 
that you're talking about. After the Second World War, these objective drivers of environmental destruction, which have to do with a growth imperative (for short, we can come back to that) the rate at which our destruction is increasing is actually accelerating, it has been increasing for the past sixty years or so. What's interesting and I think quite perplexing (in what you bring up here) is that our concern about our own destruction of the environment has also been occurring at the same time. How do we make sense of this? I say this is a paradox, and what I think is paradoxical about it is that environmental problems are becoming increasingly visible and less deniable - although there is this issue of climate change denial and so forth-but they are also becoming less and less recognizable. What I mean by that is, certainly one could say, "Well, there is no need that increasing attention to these problems should lead directly to action," or something like that. This can be explained because of vested interests or widespread denial, or cynicism, something like that. But my interests in critical theory, from a critical theoretical perspective, is saying that it is actually paradoxical about these two synchronous developments is that there hasn't been some revolutionary change in human culture worldwide - based on this objective imperative to do so. It is something beyond our control to do something about at least alleviating or decreasing the rate at which our destruction is increasing. This has really been a core paradox that I've been engaging as a way to tap into the necessity of a critical theoretical approach. Suggesting that something has not been identified; there is an underlying dynamic at work that we are not naturally at a position to understand-which indicates the need for understanding these issues theoretically. We're not socialized to think about things like alienation, the way that society works, people are socialized correctly, estranges us from nature, other people, and prevents us from consciously recognizing that this is indeed the case. And so I think there is a need and a role for social theory and critical theory, to name these underlying dynamics. 
ALVORD: This question is not worded correctly, but you mention something interesting about alienation. From my understandings of Marx and alienation is that it's sort of alienation from yourself and other workers and that kind of stuff. But you seem to be using it in an environmental context. So what does environmental alienation mean?

STONER: Alienation I think is the basis for social relationships in modern capitalist society. I think it's important, and the concept is useful and all in helping us understand this and think about it as a dynamic process. It's a form of mediation between these two dimensions of the environment-society problem that I mentioned earlier: the objective dimension and the subjective dimension. It's a form of mediation between ourselves and the natural environment. Specifically with Marx, he's talking about not labor in general, not some general metabolic interaction between humans - specifically alienated labor-and alienation in this sense is self-generated domination. That people are forced-well, they're free to sell their labor, to buy stuff-but they don't have any control over that aggregate effect of [that relationship]. The aggregate effect of those actions, we can't actually control this. And there is something about-again, Marx names this dynamic as alienation-it's still occurring today. The longer alienation is in place, the more difficult it is to recognize. So with Lukács, others have pointed this out, reification is out of this alienation as second nature, basically. Alienation is related to degradation of the environment because part of that work, that alienated labor, is related to how we value things. It's caught up in our very notions of value. Value is contingent on time, basically... We see it with an advanced capitalism: the way to make profit is to introduce technologies and so forth, decrease the amount of socially necessary labor-time, produce more stuff-we see a tendency to produce more and more stuff in less and less time. And alienation is the basis for this dynamic that we see happening. We don't get into account alienation we basically get an understanding of Marx's [view of] economics. So it has concrete implications for the accelerating rate of biophysical throughput that we see occurring in the latter half of the twentieth century. 
ALVORD: Along those same lines, you're using critical theory specifically to address why there hasn't been - in the face of this environmental threat-why there hasn't been basically a revolution of some kind. Why haven't people addressed this? Critical theory has a long history of addressing "why hasn't there been a workers' revolution" and all that kind of stuff. I guess all of this is leading up to this question of what does critical theory bring to environmental sociology or environmental studies? Or to put it another way, what is the agenda of a critical environmental studies person?

STONER: This is probably a book project, and you know at least one book, a recently edited volume, looking at critical theory perspectives, I think at the very least what critical theory does, or a critical theory of the environment does, how it's distinct from let's say a critical sociology of the environment or some other types of approaches that one might take is that it connects the subject and the object-we mentioned the environment and society problematic. In other words, a critical theory of the environment shows it must be rooted in an explanation of the destruction of external nature and so-called internal nature. That both of those are actually codetermined by the same historical process. And so, initially how I got into this stuff as a graduate student was kind of a certain impatience the certain notion that kind of came with the certain notion that I found kind of... people are concerned with environmental issues, that we just need to get the knowledge out there. People need to get involved with climate change is happening, this is a real issue, as if, as soon as we got our facts straight, this would automatically translate into some kind of recalibration of how we organize ourselves socially. In fact, a lot of people that are writing stuff like that are now showing that this wouldn't be the case, we're actually going in the opposite direction. So what I think is missing in those types of alarmist, "we just need to acknowledge the reality of climate change" or something like that and we can all get in line is social mediation. Social mediation is crucial. What's missing there is also this subjective dimension, or what [is] termed, the subjective form of appearance. That is, how people experience reality in capitalism. 
That's the dimension that I'm interested in. But like I said, we cannot be understood separate from the objective dimension, or the actual, concrete, political-economic drivers of transformation. The actual ways we transform the earth is connected to this subjective dimension. Those two things need to be highlighted in their relationship. And I think critical theory is in a good position to tell us something about that.

ALVORD: Connecting subjective-objective and that mediation, as being absolutely crucial. I'm wondering the role of scientists or experts in that process of mediation.

STONER: Yeah this is a big issue - actually another book's worth of stuff to deal with here, so I probably won't be able to answer this adequately, but there is a real issue going on here with how we know what we know about global environmental problems is actually wrapped up in that same destructive process that's driving these problems. Science in the sense of an analytical approach in these issues is necessary. If we didn't have stuff like computer modeling, and so forth, we wouldn't know anything about climate change or the state of our knowledge today about climate change today would not exist as it does. But we need to recognize that that's also wrapped up in a certain process. It's not to say again, that it's false or something, but that recognition how science is bound up with the destruction of the environment needs to be taken into account.

This is kind of an unresolved issue, also with critical theory that has been in the dialectic of enlightenment, the domination of nature, this idea of the domination of nature in general, involved science ... If you think about science, there's also (talking about enlightenment) there's also this notion that science should have a liberating effect. That science should be able to help us solve social problems and also environmental problems. So it doesn't just tell us that these problems exist but it should help usthrough the scientific method-solve problems. Yet, it hasn't filtered into our social institutions in this sense. We don't use science to solve poverty on a mass level. We don't assume that science is being used in the sense to have our destruction 
increasing. Science has been used to produce lots of products, it's been used for advertising, been used for all other things. What I'm getting at here is that in a repressive society, this is something many critical people and Marcuse was getting at, in a repressive society science will serve repressive ends. Science in itself or technology is not bad. But when a society is repressive and science and technology are being used for repressive ends. In other words, the world that we create is controlling us as opposed to the other way around. The potential for overcoming a specific form of domination that we see emerging in modern capitalist society and that's related to the domination of nature, is there. We have the science, we have the knowledge, we have the technology. I'm not a climatologist, I don't know the specifics of this stuff but I do know we at least have the scientific knowledge to decrease our rate of destruction - we can organize ourselves differently. That's not being controlled by us. And that has something to do with capital.

ALVORD: I loved how you said that. Coming out of the Enlightenment, the idea that science should be liberating, but we don't use science to actually be liberating. Science is used as a means of further domination: We can understand how people shop, or targeted advertising or something like that. How does that translate into environmental studies or environmental values? In other words, how have people's feelings on the environment been influenced by a certain form of science that we have?

STONER: Conservation biology, let's say for example, and modern ecology in general, use scientific approaches, right? They typically have defensible, admirable, normative aspect, that is that we should use this knowledge to... there is a concern about the destruction of the environment. There's an obligation on the part of the scientists to use this knowledge for purposes of sustainability or something like that.

What I think is not taken into account is this issue of mediation. I attended a talk not that long ago, a great talk by a climatologist, whose into some great information, some great historic information 
about climate change and how humans are causing climate change. And then went on to present some critical, rational alternatives to how we might deal with this. What I thought was missing is what's actually enabling that change, or in other words, mediation. And again, in the society that we live in, science will be used for certain ends. To use if for purposes of, let's say, emancipation, that possibility is here, but it would require, I think at least this is in relation to the whole critique, paying attention to what's currently keeping it from playing an emancipatory role. For example, in relationship to nature. This is actually a big issue because what's not taken into account is mediation.

ALVORD: Mediation being, what's inhibiting change?

STONER: The social mediation, in terms of how we relate to the environment. And the main processes of mediation that I've talked about are alienation, which we discussed very briefly, and reification, which for sure missed as alienation's second nature. These are processes. We are continually reproducing them. They are the basis of our social relationships. And if that stuff is ignored, then, de facto, the approach will risk falling into ideology and justifying the existing system if that's not taken into account. So the role of critique - from my perspective - is to pay attention to those types of things. What's inhibiting change? But also, there's the other end, which is that, the role of critique is not just an analytic approach. It's not just to describe the state of affairs. Like I said there's a great historical, economic research looking at the objective drivers of global environmental problems. Critique means to pay attention to the conditions of possibility for another world. That another world is possible, to use the slogan here... That goes along with the critical theory approach.

ALVORD: Along those same critique lines, your most recent research project is on critiquing the Anthropocene. First of all, what is the Anthropocene? 
STONER: The Anthropocene is this term that was recently popularized by this pretty well-known Nobel Prize-winning chemist Paul Crutzen. Initially in this article from 2000, and the commentary on the article that came out in Nature in 2002, and it's gained quite a bit of traction lately. Basically this term is meant to indicate a change in the history of the relationship between humanity and the planet, in which what's driving global changes and earth system processes, for the first time in history, is human activities. Crutzen dates this to basically the industrial revolution during the latter half of the eighteenth century. And like I said, it's gained quite a bit of traction; the Anthropocene in this sense would be a distinction from the Holocene-our current geological epoch. It's the epoch that gave rise to human civilization, and from what I know, there's been myriad scientists that's going to be deciding officially whether or not to officially recognize the Anthropocene as this new era of planetary history. That's supposed to be decided by 2016 .

So in terms of the critique of the Anthropocene, the idea is significant, because it grasps something about the relationship between modern society and the environment. The latter half of the eighteenth century, the industrial revolution, this is also the emergence of what we call modern society, so it paints a pretty clear picture in other words that modern forms of social organization are the cause of our current ecological predicament. In this sense it does grasp some things significant about societyenvironment relationships. My critique of the concept is that it is unable to account for the historical specificity of the relationship between the environment and society. And more specifically, it's unable to account for that paradox I mention. And so, the big blind spots with characterizing the past 250 years that should be known as the Anthropocene, this new epoch, is that it's unable to deal with fact of how a society emerges from the industrial revolution can be both conscious of its degradation of the environment and seemingly helpless in doing anything about it. And so what I say in this critique of the Anthropocene is that is actually projects our helplessness in the present 
backward over the past 250 years. And this sense, it naturalizes what is historically specific about the relationship between modern society and the environment. This helplessness comes at the close of the twentieth century that seems to foreclose this very idea of the capacity of society to transform itself. And this wasn't always the case. And in fact, it is the result of the cumulative failure of past revolutions. So in the paper I provide a more subtle, useful, and reflexive account of what the Anthropocene actually is. And a critique about itself, because like I said it does grasp something specific, but it risks naturalizing this helplessness which is historically specific. If that's not recognized, then there's political implications. If we can recognize that this helplessness is historically specific, created by humans, then that implies the possibility of change. But, this sort of precondition for effective change would be working through the past in this sense. The paper is really kind of begging, in a certain way, what the meaning of the Anthropocene is, what does this mean-especially with regard to the capacity of society to self-consciously transform itself?

ALVORD: As I understand your critique is that the Anthropocene is almost too large a swath of time? Does that make sense? The helplessness is projected backwards 250 years, but at our modern stage in society, we feel helpless. The Anthropocene projects that backwards and says, "We've always felt helpless." Am I understanding that?

STONER: Yeah, it doesn't recognize this helplessness. That's one of the things I'm trying to point out. Is that the very... ostensibly we're at 250 years into the Anthropocene, so the recognition comes with a pretty conspicuous lag. Why this recent turn? That's one of the questions that motivate the paper. How do we explain this recent interest on the part of environmental sociologists, scientists, the public, in this whole idea? And that very interest is actually historically specific. What is suggest is that interest itself is bound up with a sense of helplessness that only comes at the late end of the twentieth century. Someone, Paul Crutzen, popularized this idea of the Anthropocene, and dates it, and puts 
it in one piece a specific date of 1784 which is when James Watts invented the steam engine. But it's kind of interesting to think about how James Watts wouldn't have thought about the Anthropocene and this potential destruction of all life on earth. He probably would've held on to this idea that humanity was driving history.

What hasn't been mentioned and what's the core aspect of the paper is the idea of freedom. Someone like James Watts would've held on to the idea of freedom and the political project of freedom, and overcoming the constraints of feudalism, for example. Our moment, today, the beginning of the [twenty-first] century, is marked by this dramatic continuation, or even distrust that such a transition is even possible. So what's going on there? What happened? And also, this is related to that paradox: the paradox of increasing concern, and increasing degradation. What's understated, typically, is our apparent inability to do anything, to change the situation. And so oftentimes, and this is coming from how I understand (in an environmental sense) the Anthropocene, is it looks to an outside catastrophe or an impended disaster that would motivate humanity to reconfigure itself, or somehow solve these problems in a more rational manner. This is quite different from the idea of the Enlightenment, in which man is consciously controlling history from within, taking into account the idea of freedom. I'm basically trying to clarify some of my concerns if we adopt this idea of the Anthropocene, while recognizing that it does say something significant, especially with regard to these objective drivers. Crutzen and his colleagues have presented some pretty provocative and quite alarming graphs and these spikes they call the great acceleration from 1950. They present these key indicators of human activity and how this is basically related to changes on a global scale of earth system processes and it's kind of alarming.

ALVORD: This is all very interesting. So you're working on this project now. Where do you see this going? What's your future work? How do you plan on continuing this in some way?

STONER: I'll probably be working through. The dust has yet to settle, so to speak, with this Anthropocene paper. I have the 
opportunity to talk about it at KU last night, and I'll let that marinate, probably for a little bit. Then I have another project that's looking at ecological economics, specifically, value. It's kind of a point of confusion for ecological economics - and arguably the crucial issue. Ecological economics has this issue of value. I'll be touching on some of the literature of ecosystems management.

And then I have a project specifically that will look at, again, the relationship after-I'm interested in this post-World War II period-so I'm going to be looking more specifically at the relationship between some of these political-economic drivers and our social conception and understanding of the environment, focusing in on developments that occurred in American society for example with the development of the military-industrial complex. This explosion in technology that in many ways (and a lot of people have been doing this as well) is related to our current conception of nature. In fact how we understand nature today would not have been possible without the explosion in technologies that comes out of the military-industrial complex. And given that these technologies were originally produced for the purposes of violence, what does that mean in terms of how we see ourselves with regard to nature and how we actually conceive nature.

And then, finally, a bit long-term, in a few years, there's a book that needs to be written on critical theory and the environment. And also this issue of throughput which I think I mentioned once, is really quantitatively there's measurements for it, in "biocapacity" which is used, and "ecological footprint," which is relatively well-known, is a proxy for throughput. But theoretically, I think it's kind of unspecified. It's at least a bit confusing to me, so I'm also kind of interested in trying to understand exactly what throughput is and what it would meanconnecting this to some of the things I've said earlier-that throughput has been accelerating. Because, we can't measure this. How do you measure something like throughput where the reference point involves a rate when the rate itself is changing? Which, this is something I didn't talk about which is Marx's theory of ... Time actually moves forward. This is something Postone talks about, he is another theorist I look at, is that the time determines the amount of stuff being produced is actually moving forward; so in this instance, there is more and more 
stuff produced at less and less time. So how do we understand that?

And there's actually some recent work, this person, Rosa, put out a book, called Social Acceleration. It seems like there is an emphasis on understanding the temporal structures of society, kind of temporal sociology. This idea that society, modernity, which is something going on here and has to do with acceleration, and arguably, this has implications for the environment - especially with regard to throughput. So those are three very general-some short-term, some long-term - projects that I have in the works.

ALVORD: Right. Wow. Well, I look forward to it. Dr. Stoner, thank you so much for joining us today. It was awesome to talk to you.

STONER: Great. Thank you. 
